Çukurova Üniversitesi Mühendislik Mimarlık Fakültesi Dergisi, 30(2), 115-123 ss., Aralık 2015

Çukurova University Journal of the Faculty of Engineering and Architecture, 30(2), pp. 115-123, December 2015

\title{
Çelik Bir Bacanın Dinamik Davranışının Analizi
}

\author{
Gökhan GÜRSOY*1, Hüseyin R. YERLi் ${ }^{1}$, Selçuk KAÇIN ${ }^{2}$ \\ ${ }^{1}$ Çukurova Üniversitesi, İnşaat Mühendisliği Bölümü, Adana \\ ${ }^{2}$ İskenderun Teknik Üniversitesi, İnşaat Mühendisliği Bölümü, Hatay
}

Geliş tarihi:15.09.2015

Kabul tarihi: $12 \cdot 10.2015$

\section{Özet}

Giderek artan endüstriyel tesislerin (termik ve nükleer santraller, demir çelik fabrikaları, değişik imalata yönelik fabrikalar) ihtiyacı olan endüstriyel bacalar için ülkemizde henüz bir standart bulunmamaktadır. Yine bu yapıların modellenmesi için paket programlar kullanılmakta ancak gerçek davranışı hakkında saha çalışmalarına gerek duyulmaktadır.

Bu çalışmada Hatay ili İskenderun ilçesinde yer alan, Türkiye'nin en eski demir çelik fabrikalarından biri olan İskenderun Demir ve Çelik A.Ş. (İsdemir)'nin 3. Yüksek firın soba bacası incelenmiştir.

Anahtar Kelimeler: Baca, Yapısal analiz, Mevcut titreşim.

\section{Determination of a Steel Chimney's Dynamic Behavior}

\begin{abstract}
Increasingly, industrial facilities (thermal and nuclear power plants, steel mills, factories for different manufacturing) for industrial chimneys in need in our country does not yet have a standard. Software packages are used for modeling of these structures and field works are needed to identify real behaviour of these structures.

In this study Located in the town of Iskenderun of Hatay province, one of the Turkey's oldest iron and steel factories, İsdemir's 3 Blast Furnace Stoves Chimneys were investigated.
\end{abstract}

Keywords: Chimney, Structural analysis, Ambient vibration.

\footnotetext{
*Yazışmaların yapılacağı yazar: Gökhan GÜRSOY, Çukurova Üniversitesi, İnşaat Mühendisliği Bölümü, Adana.e.eng.gursoy@gmail.com
} 


\section{GíRiş}

Bacaların dinamik davranışları çok uzun yıllardan beri mühendislerce incelenmektedir. Başlangıçta sadece tuğladan yapılan yüksek bacalar, daha sonraki yıllarda betonarme olarak imal edilmiş ve daha sonra da çelik bacalar üretilmiştir. 19. yüzyıl sonlarından 1950'li yıllara kadar yapılan bacaların hemen hemen hepsi tuğla bacalardan oluşmaktayd 1 (Pallares vd. 2006) [1]. Günümüzde kullanım amacına, yüksekliklerine, tiplerine göre çok farklı şekillerde sinıflandırılabilen bacalara rastlanmaktadır. Aşırı rüzgar yükü sebebiyle veya deprem etkisiyle yıkılan bacalar oldukça yüksek yapılar olduklarından yıkıldıklarında da çevresindeki büyük bir alanı etkilemektedir. $\mathrm{Bu}$ sebeple bacaların dinamik davranışı konusunda yapılan çalışmalar oldukça eskiye dayanmaktadır. Son yıllarda ise özellikle kullanılmayan eski tuğla bacalar birer kültürel miras olarak görülmekte ve bu bacaların güçlendirilerek korunması konusunda çalışmalara rastlanmaktadır (Pallares vd. 2011) [2]. Baca gibi yüksek yapılarda önemli yıkıcı etki olan rüzgar yükü etkisi altında bacaların dinamik davranışlarının incelendiği çalışmalar da mevcuttur (Sanada vd. 1992) [3].

Son yıllarda teknolojideki hızlı gelişmeler inşaat mühendisliğinde de önemli aşamalar kaydedilmesini sağlamıştır. Bu gelişmelerden en dikkat çekici olanı yapının dinamik davranışının incelenmesi konusunda izlenen yöntemlerdir. Eskiden laboratuvar testleri veya analitik yöntemler ile çözülen birçok problem günümüzde gerçek yapılara kurulan izleme sistemleri sayesinde daha doğru olarak hesaplanabilmektedir. Eskiden yapıların deprem altındaki dinamik davranışı analitik modeller veya sarsma tablaları üzerine kurulan küçük ölçekli modeller üzerinde yapılan araştırmalar ile yapılmaktaydı. Günümüzde ise yap1 izleme sistemleri sayesinde deprem bölgelerindeki yapılara aletler yerleştirilerek alınan deprem verileri yapıların deprem davranışı konusunda gerçekçi bilgiler vermektedir. Mevcut yapılardan alınan verileri laboratuvar ortamında yapilan deneylerden ve analitik modellerden alınan verileri geçersiz kılan değil, tamamlayan veriler olarak düşünülmelidir.
Yapı izleme sistemleri ikiye ayrılır: Bir tanesinde yapıya cihazlar yerleştirilip deprem esnasında okuma alınır, diğer yöntemde ise mevcut titreşimler sensörler vasıtası ile kaydedilir. Mevcut titreşimlerin ölçülmesinde de iki yol kullanılabilir. Bunlardan birincisinde yapıya titreşim üretici cihaz ve bu titreşimleri kaydedebilecek sensörler yerleştirilir (zorlanmış titreşim deneyleri), ikincisinde ise titreşim üretici cihazlara ihtiyaç duyulmadan yerleştirilen sensörlerden mevcut titreşim (ambient vibration) kayıtları alınır.

California'da yapılan Zorlanmış titreşim ve mevcut titreşim testleri yaklaşık 65 yıldır yürütülmektedir. The U.S. Coast ve Geodetic Survey mevcut titreşim analizleri ile yapılan temel periyodlarını ölçmeye 1930'ların başlarında başladı. Yaklaşık 30 yıl sonra Crawford ve Ward, 1964 [4] bu testi inceledi ve yapıların titreşim modlarının ve düşük frekanslarının belirlenmesinde kullanılabileceğini gösterdi.

Trifunac (1972) rüzgarı ve mikro sarsıntıları çerçeve sistem yapıların testinde kullandı. Birkaç yıl sonra mevcut titreşim analizlerinin sonuçlarıyla aynı iki bina üzerindeki zorlanmış titreşim testinin sonuçlarını karşılaştırdı. İki testin de sonuçları benzer ve tutarliydı [5].

Mevcut titreşim analizlerine 1990 ve 2000'lerde daha derin çalışmalarla katkı sağlanmaya devam edildi.

Mevcut titreşim analizinin en sık kullanım alanlarından biri de doğal frekansların titreşimlerinin yapıların mod şekillerinin bulunmasını içerir. Mevcut titreşim analizleri, aynı zamanda parametre tahminlerini ve yapiların model özelliklerini geliştirmede kullanılır.

Cracow University of Technology, ve Building Research Institute, Polonya'da yapılan çalışmalarda $100 \mathrm{~m}$ uzunluğundaki yeni bir çelik bacanın rüzgar etkisi altındaki titreşimler sonucu bulonlarında oluşan hasarların nedenleri incelenmiştir. Baca ve paralel bina mevcut mod ve frekansları ölçülerek mevcut yap1 davranışlarının farklılıkları üzerinde durularak hasarın nedeni açıklanmıştır [6]. 
Bu çalışmada İskenderun Demir Çelik Fabrika sahasında içerisinde yer alan yaklaşık 65 metre yüksekliğindeki 3. Yüksek Fırın (3.YF) bacasının dinamik özelliklerinin mevcut titreşim kayıtları ile belirlenmesine çalışılmaktadır.

2006 yılında inşaatı gerçekleştirilen baca, betonarme kazıklı temel üzerine oturmaktadır. Bacaya yüksek firın gazı refrakter kaplı bir kanal vasıtası ile gelmektedir. Gaz tünelinden gelen yüksek firın gazı baca içerisinden geçerek emisyon kontrolü ile birlikte şarj edilmektedir.

\section{MATERYAL VE METOT}

Bu çalışmada İSDEMİR A.Ş.'de bulunan çelik bacadaki mevcut titreşimler ölçülerek bacanın bazı dinamik karakteristik özelliklerinin bulunması amaçlanmıştır (Şekil 1). Bu amaçla sensör yerleşimleri yapılarak titreşim kayıtları analiz edilmiş ve paket program yardımı ile yapı modellenerek sonuçlar karşılaştırılmıştır.

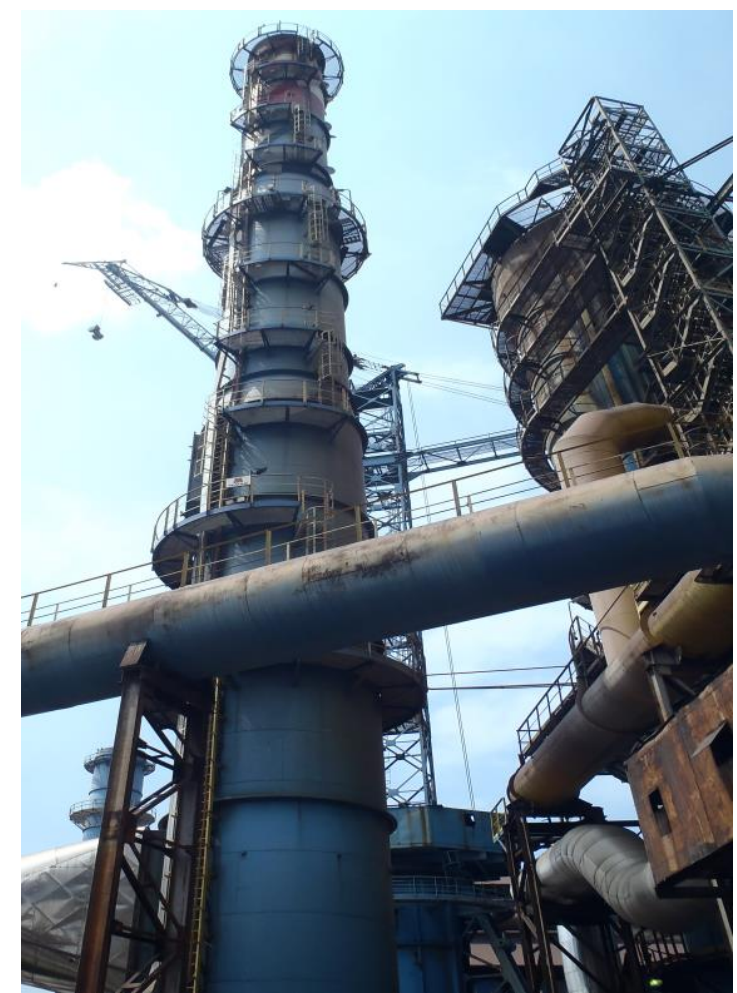

Şekil 1. Baca genel görünüşü

\subsection{Materyal}

\subsubsection{Hizölçerler}

Hız ölçüm cihazları üç bölümden oluşmaktadır, bir adet hız sensörü, bir adet dönüştürücü ve bir adet kayıt kutusu (Şekil 2). Bu sistemdeki cihazların birbiri ile bağlantısı şu şekilde yapılmaktadır; hız sensörü üzerindeki su terazisi ile dengeye getirildikten sonra kablo ile kayıt ünitesine bağlanır. Bir dönüştürücü ile ana kayıt ünitesine (Network Control Centre) bağlanır. Sensörler yapıdaki mevcut titreşimleri algılar ve kaydeder.

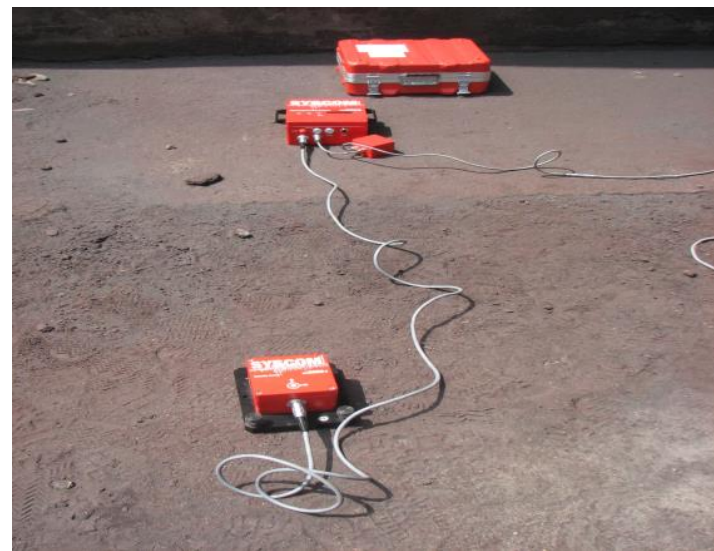

Şekil 2. Hız sensörü ve bağlantıları

\subsection{Yöntem}

\subsubsection{Serbest Titreşim Hareketi}

Çok serbestlik dereceli sistemlerde serbest titreşimden doğal modlar bulunur. Çok serbestlik sistemlerde serbestlik derecesi sayısı kadar doğal mod ve bunlara karşılık gelen doğal titreşim periyotlar1 mevcuttur. Sistemin koordinat noktalarının yer değiştirmelerinin birbirlerine oranları serbest titreşimin herhangi bir zamanında sabittir. Genel denklemden, sönüm kuvvetleri ve dış kuvvetler çıkarılırsa, çok serbestlik dereceli sistemin, serbest titreşim hareket denklemi elde edilir. Genel dinamik hareket denklemi;

$m \ddot{x}(t)=P(t)-k x(t)-c \dot{x}(t)$

veya 
$m \ddot{x}(t)+c \dot{x}(t)+k x(t)=P(t)$

şeklini alır. Kütleyi harekete zorlayacak dış etkenler bulunmaması halinde ise, sistemin serbest titreșim denklemi şu şekildedir:

$m \ddot{x}(t)+c \dot{x}(t)+k x(t)=0$

\subsubsection{Sönümsüz Serbest Titreşim}

Diş zorlamalar sona erdikten sonra sürmeye devam eden salınımlara serbest titreşim denir. Serbestçe titreșen, tek serbestlik dereceli bir sistemde sönüm olmadığı varsayılırsa, hareketi tanımlayan denklem;

$m \ddot{x}(t)+k x(t)=0$

halini alır. Denklem şu şekilde yazılabilir;

$\ddot{x}(t)+(k / m) x(t)=0$

Buradan sönümsüz serbest titreşim frekans1;

$\ddot{x}(t)+\omega^{2}(x(t))=0$

$\omega^{2}=k / m$ ve $\omega=\sqrt{k / m}$

olarak yazılabilir.

\subsubsection{Sönümlü Serbest Titreșim}

Tek serbestlik dereceli sönümlü bir sistemde hareketi tanımlayan denklem

$m \ddot{x}(t)+c \dot{x}(t)+k x(t)=P(t)$

Şeklinde olup, $\mathrm{x}=\mathrm{e}^{\alpha \mathrm{t}}$ olarak ele alındığında denklem,

$m \alpha^{2}+c \alpha+k=0$

halini alır. Buradan hareketle;

$\alpha^{2}+(c / m) \alpha+(k / m)=\alpha^{2}+2 \xi \omega \alpha+\omega^{2}$

olarak elde edilir.
Sönüm oran1;

$\xi=c / 2 \omega \mathrm{m}$

olarak bulunur. Çözümü geçerli kılacak $\alpha$ değerleri 3.11 denkleminin kökleridir. Dolayısıyla bu değerler;

$\alpha_{1}=-\xi \omega+\omega \sqrt{\xi^{2}-1}$

$\alpha_{2}=-\xi \omega-\omega \sqrt{\xi^{2}-1}$

olarak hesaplanır [7].

\subsubsection{Deneyin Yapılıșı}

3.YF Soba Bacası bulunduğu bölge itibari ile yoğun rüzgar yüklerinin yanı sıra temele 10 ila 20 $\mathrm{m}$ mesafelerde sıcak maden geçişini sağlayan demiryollarının yanında yer almaktadır. Proses gereği yüksek firına yüksek tonajlarda hammadde beslemelerinde titreşimlere maruz kalmaktadır.

Deney sırasında taşıma işlemleri için 1000 tonluk BK1000 vinci kullanılmıştır. 28.04.2014 tarihinde sensör yerleşimi için yüksekte çalışabilir, ağır ve tehlikeli işlerde çalışabilir raporlu çalışana sensör yerleşimleri ve bağlantıları konusunda baca tabanında detaylı bilgiler verilmiştir. Burada sensörlerin (MR) aynı doğrultuda olmaları ve aynı yöne bakmaları büyük önem arz etmektedir. Uygulamalı olarak yapılan bilgilendirmenin ardından iş güvenliği açısından emniyetli bir şekilde sensörler Şekil 3-5'de görülen sira ile yerleştirilmiştir.

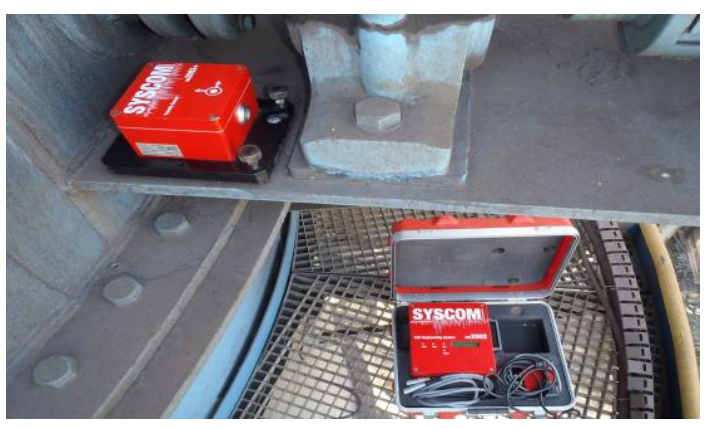

Șekil 3. Sensör bağlantıları 


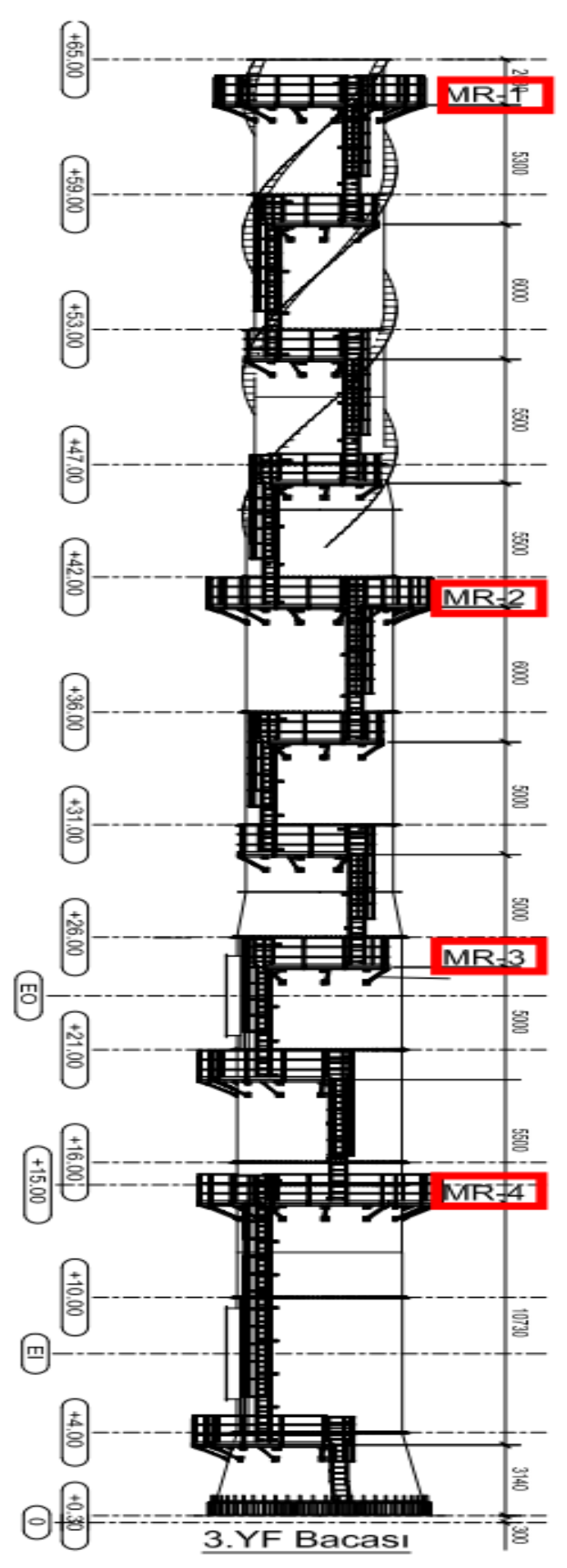

Şekil 4. 3.YF soba bacası sensör yerleşimleri

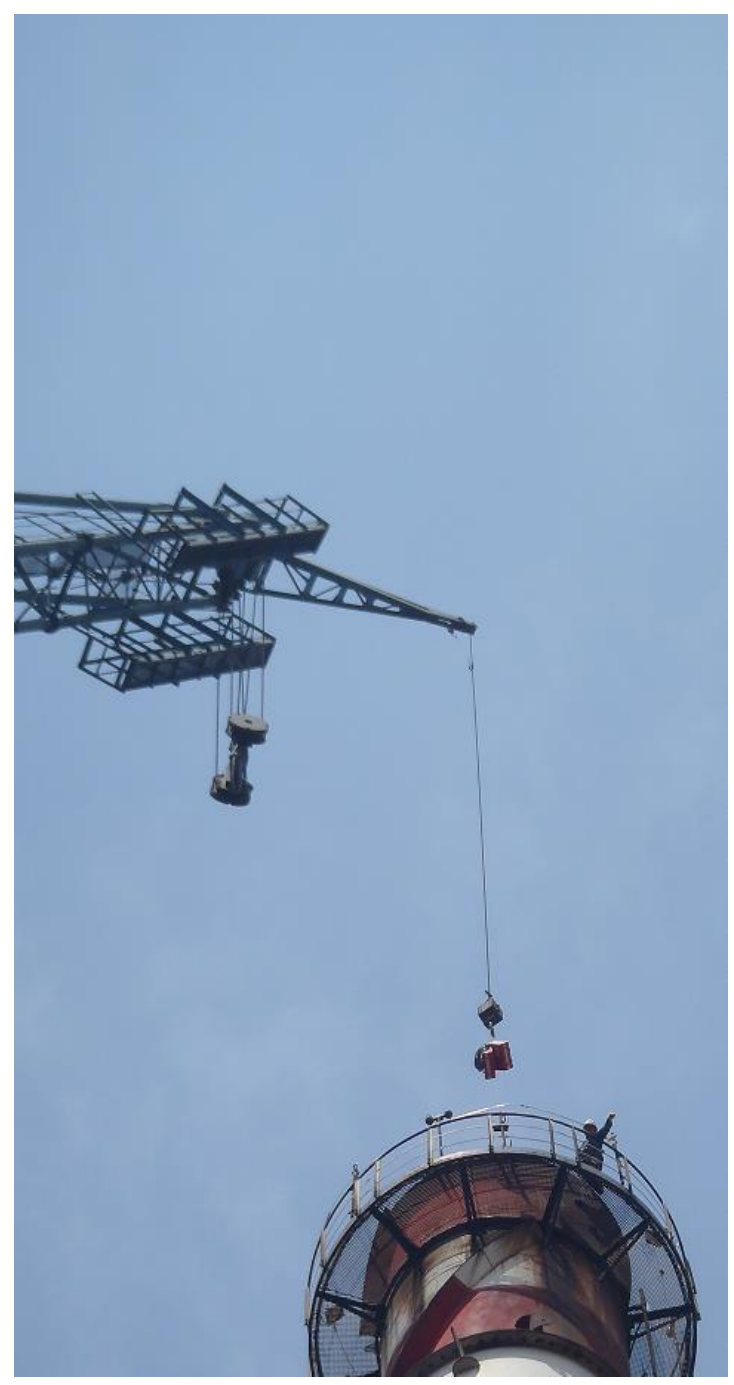

Şekil 5. Sensörlerin taşınması

\section{BULGULAR}

\subsection{Deney Sonuçları}

\subsubsection{Data Analizi}

Deneyler sonucunda elde edilen verilerin işlenmesi VIEW2002 paket programı ile yapılmıştır. Aletlerden alınan kayıtların analiz edilmeden önce veri işleme denilen bir data temizleme işleminden geçirilmesi gerekir. Bu işlem analizi kolaylaştırdığı 
gibi hata oranlarını da azaltır. Bu kayıtlar için veri işlemesi aşağıdaki adımları kapsar (Şafak, 2007):

1. Datadaki ortalama değerlerin ve lineer hataların ayıklanması (base-line correction).

2. Kayıtlarda gürültünün fazla olduğu çok düşük ve çok yüksek frekanslı kısımların filtre edilmesi.

3. Yapıda mevcut en yüksek frekans değerleri göz önüne alınarak gerekirse kayıtlardaki örnekleme aralığının yükseltilmesi (decimation)

4. Eğer sensörlerden alınan kayıtlar senkronize değilse analitik yöntemler kullanılarak kayıtların senkronize edilmesi.

\subsubsection{Modal Frekansların Bulunması}

Yapının modal frekanslarının bulunması en basit yolu işlenmiş datanın Fourier transformunu almaktır. Fourier transformu esas olarak datanın sonlu sayıda sinüs eğrisinin genliklerini değiştirerek ve birbirine göre kaydırarak toplanmasına eşdeğer hale getirilmiş işlemidir. Fourier tarnsformunda genliğin maksimum olduğu frekanslar yapının modal frekansını gösterir (Şafak, 2007).

MR adı verilen sensörlerden elde edilen grafikler aşağıda sıralanmaktadır (Şekil 6-8).

Deney sonucu elde edilen kayıtlar VIEW2002 paket programı ile analiz edilerek bacanın hakim frekans değerleri Şekil 9 ve Çizelge 1'de sunulmuştur.

\subsection{Model Sonuçları}

Deneysel verilerin karşılaştırılabilmesi açısından bacanın, sonlu elemanlar yöntemini temel alan yapısal analiz programı SAP2000 Nonlineer ile modellemesi yapılmıştır (Şekil 10). Modelleme çalışmalarında elde edilen değerler karşılaştırılmıştır (Çizelge 2). Modelde, temel, perde, refrakter ve sac elemanlar ayrı olarak tanımlanmıştır. İki ayrı yüzeyin beraber hareket etmesini sağlamak amacı ile link elemanlar kullanılmıştır.

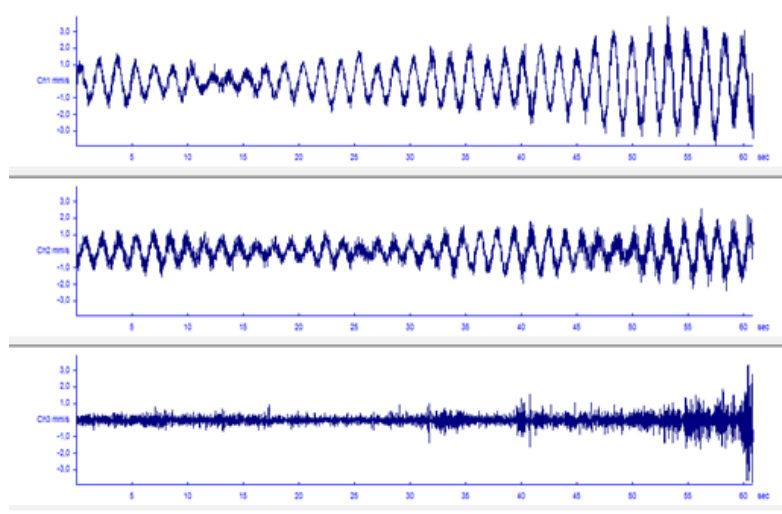

Şekil 6. 3.YF soba bacası hız grafiği
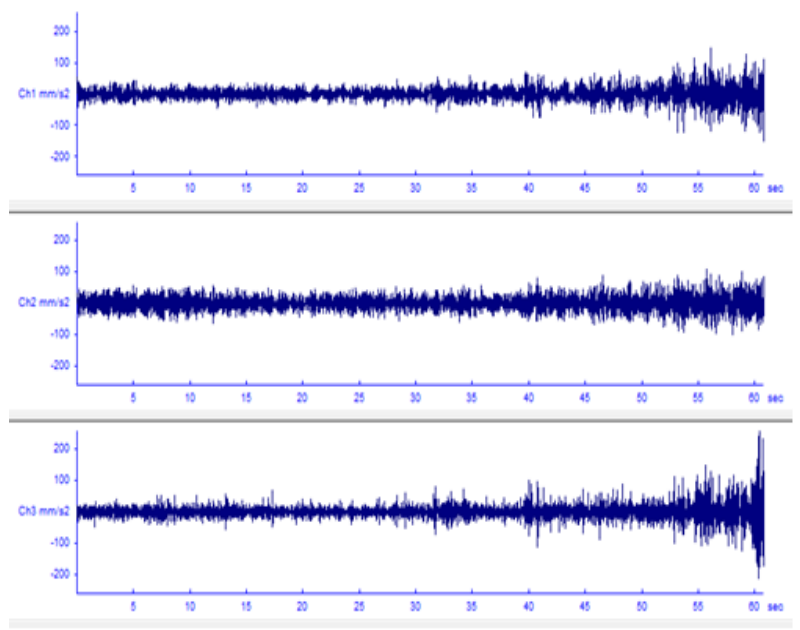

Şekil 7. 3.YF soba bacası ivme grafiği

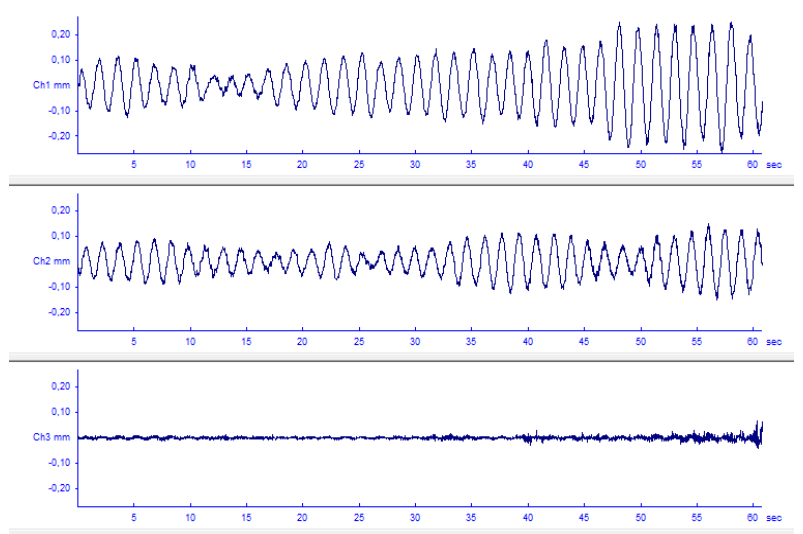

Şekil 8. 3. YF soba bacası deplasman grafiği 


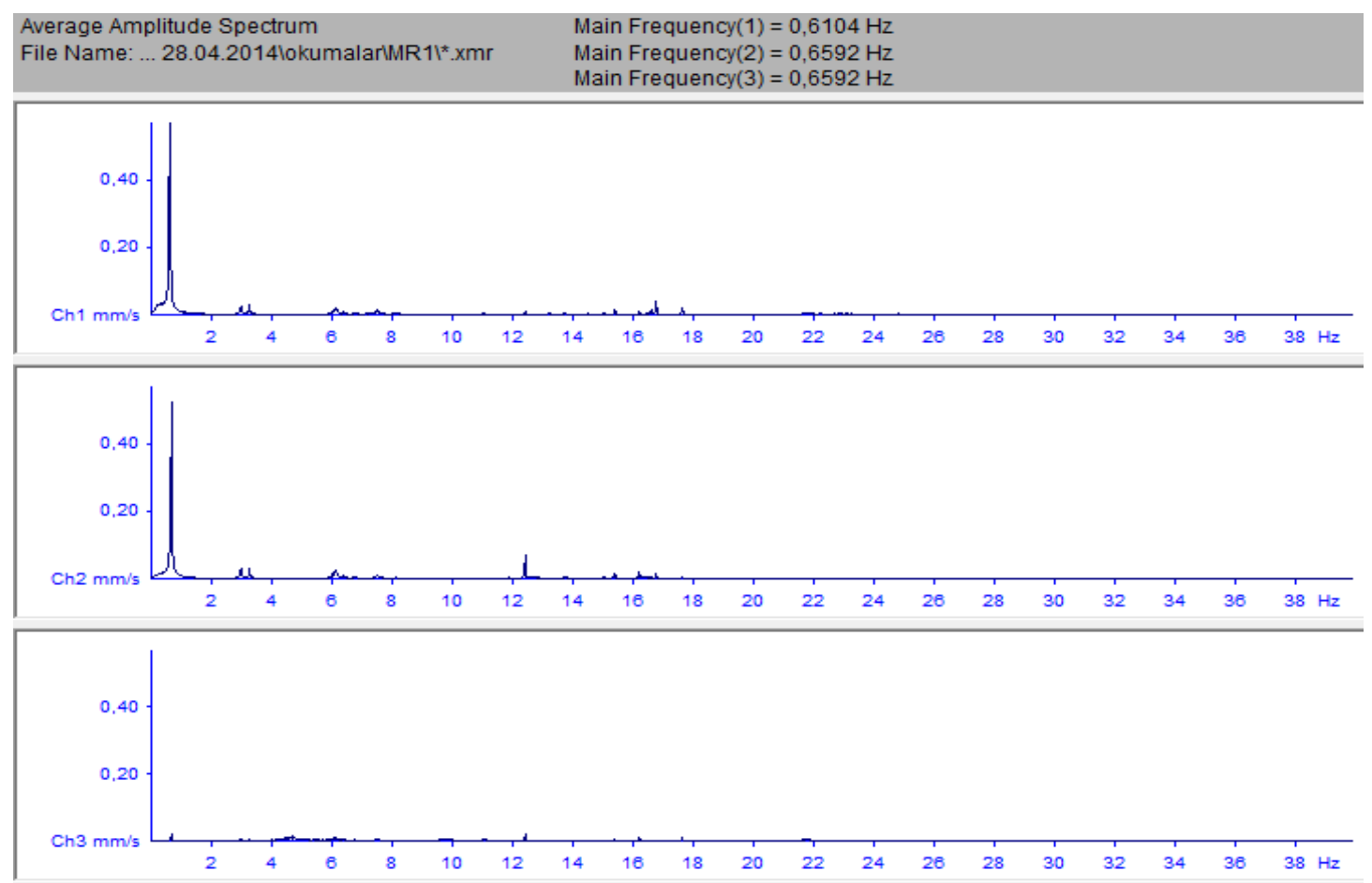

Şekil 9. 3. YF soba bacası hakim frekansı

Çizelge 1. Deney sonucu elde edilen hakim frekans değerleri

3.YF soba bacas1

\begin{tabular}{|l|c|c|c|}
\hline & $\begin{array}{c}\text { 1.Main } \\
\text { Frekans(Hz) }\end{array}$ & $\begin{array}{c}\text { 2.Main } \\
\text { Frekans (Hz) }\end{array}$ & $\begin{array}{c}\text { 3.Main } \\
\text { Frekans (Hz) }\end{array}$ \\
\hline MR1 & 0,610 & 0,659 & 0,659 \\
\hline MR2 & 0,610 & 0,659 & 12.43 \\
\hline MR3 & 0,610 & 0,659 & 0,659 \\
\hline MR4 & 0,610 & 0,659 & 0,659 \\
\hline
\end{tabular}

\section{SONUÇ}

Bu çalışma kapsamında Hatay İli İskenderun İlçesi sınırlarında bulunan İSDEMİR A.Ş. 3. yüksek firın soba bacası ele alınmış ve yapı üzerine yerleştirilen sensörlerle mevcut titreşim analizleri yapılmıştır. Yapılan deneyler sonucunda bacanın doğal periyotları ve modlarına ait mod şekilleri elde edilmiştir.
Elde edilen sonuçlar SAP2000 sonuçları ile birlikte verilmiştir.

Bacanın üzerindeki sıcaklık etkisinin değişken olması, baca giriş noktalarında salınımın engellenmesi, Google vana gibi rijit unsurların baca bağlantı noktalarında bulunması gibi nedenler ile deney sonuçları ile bilgisayar modeli mod değerleri arasında farklılıklar gözlemlenmekle 

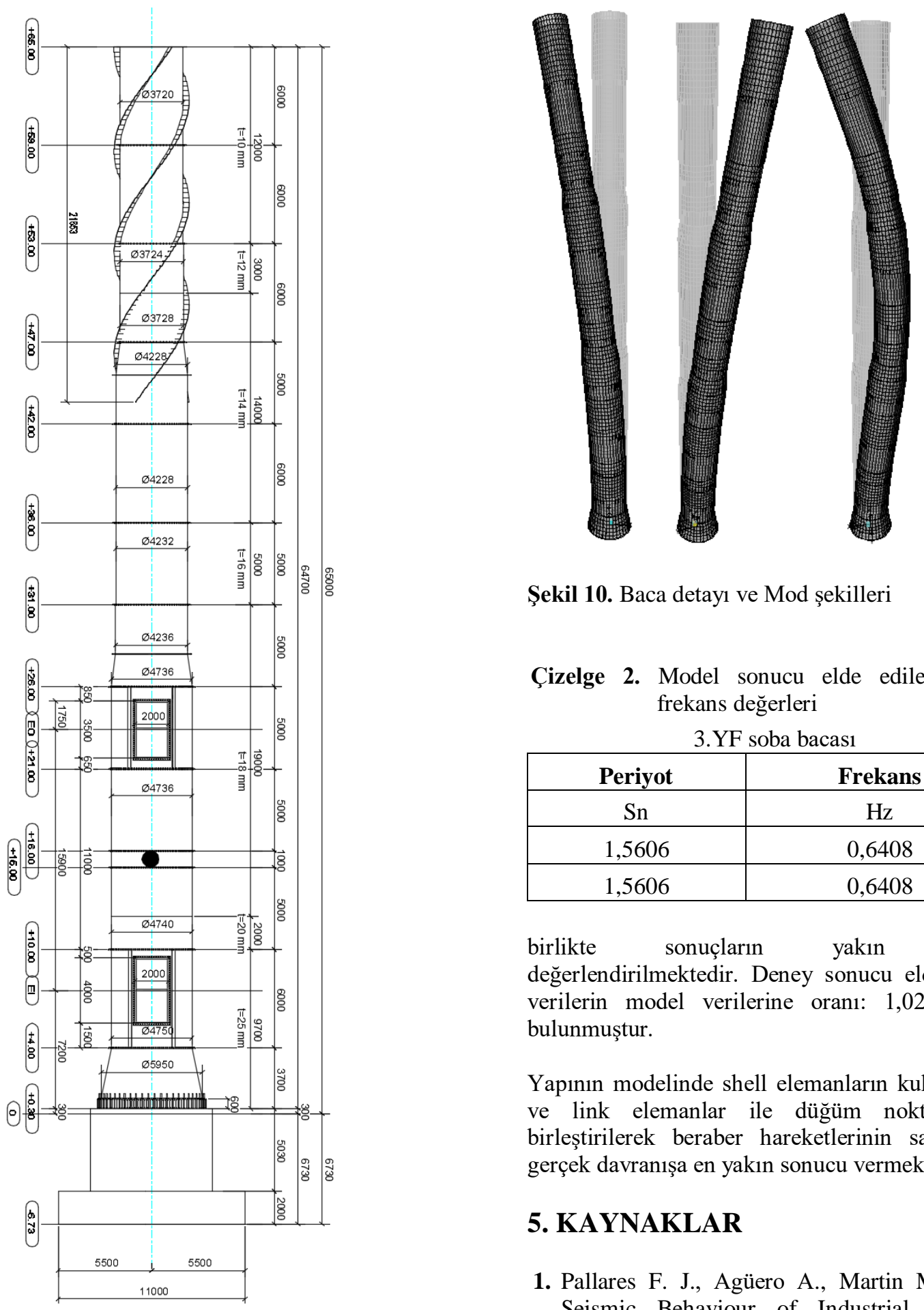

Şekil 10. Baca detayı ve Mod şekilleri

Çizelge 2. Model sonucu elde edilen hakim frekans değerleri

3. YF soba bacas1

\begin{tabular}{|c|c|}
\hline Periyot & Frekans \\
\hline $\mathrm{Sn}$ & $\mathrm{Hz}$ \\
\hline 1,5606 & 0,6408 \\
\hline 1,5606 & 0,6408 \\
\hline
\end{tabular}

birlikte sonuçların yakın çıktı̆̆ değerlendirilmektedir. Deney sonucu elde edilen verilerin model verilerine oranı: 1,028 olarak bulunmuştur.

Yapının modelinde shell elemanların kullanılması ve link elemanlar ile düğüm noktalarından birleştirilerek beraber hareketlerinin sağlanması gerçek davranışa en yakın sonucu vermektedir.

\section{KAYNAKLAR}

1. Pallares F. J., Agüero A., Martin M., 2006. Seismic Behaviour of Industrial Masonry 
Chimneys, International Journal of Solids and Structures Volume 43: 2076-2090.

2. Pallares J. F., Ivorra S., Palleras L., Adam M. J., 2011. State of the Art of Industrial Masonry Chimneys: A Review from Construction to Strengthening Construction and Building Materials 25: 4351-4361.

3. Sanada S., Suzuki M., Matsumoto H., 1992. Full Scale Measurements of Wind Force Acting on a 200 M Concrete Chimney And Chimney's Response Journal of Wind Engineering and Industrial Aerodynamic 4144:2165-2176

4. Crawford, R., Ward H.S., 1964. Determination of the Natural Periods of Buildings. Bull. Seis. Soc. Amer., 54,1743-1756.

5. Trifunac, M.D., 1972. Comparison Between Ambient and Forced Vibration Experiments. Earthquake Engineering and Structural Dynamics. Vol. 1, Issue 2, Pages 133-150.

6. Kaweckia J., and Zuranskı J.A., 2007. CrossWind Vibrations of Steel Chimneys a New Case History. Journal of Wind Engineering and Industrial Aerodynamics, Vol. 95, No. 9-11, pp. 1166-1175.

7. Yerlici V., 2007. Yapı Dinamiğine Giriş. Boğaziçi Üniversitesi Yayınevi.

8. Seismosoft, 2013. SeismoStruct - A Computer Program for Static and Dynamic Nonlinear Analysis of Framed Structures (online). Available from URL: http://www.seismosoft.com

9. SAP2000. V15 Paket Program1, 2013. Computers and Structures Inc.

10. Chopra, A. K., 1995. Dynamics of Structures: Theory and Applications to Earthquake Engineering.

11. Şafak E., 2007. Yapı Titreşilerinin İzlenmesi;Nedir, Neden Yapılır, Nasıl Yapılır ve $\mathrm{Ne}$ Elde Edilir? 6. Ulusal Deprem Mühendisliği Konferansı, 16-20 Ekim 
Çelik Bir Bacanın Dinamik Davranışının Analizi 